would recover, as, previously to this illness, she had been in a most critical state of health. Every portion of the body where the eruption made its appearance was painted over with a solution of one part of carbolic acid in twelve of glycerine. Immediately the great distress produced by the eruption was relieved, and was prevented from returning by the application being repeated night and morning. The rest of the treatment consisted in supplying plenty of fresh air and a simple yet nourishing diet. Chlorate of potash in solution was given as a drink, and the bowels were kept moving by a mild laxative given when required; and the patient passed through the whole course of the disease without an unfavourable symptom. There was no itching of the skin, and there was no secondary fever; indeed, there was no fever at all after the first application of the carbolic acid and glycerine. The patient slept well, and took her food with a relish. Within a year after her recovery, it was almost impossible to find any traces of the disease, so completely had the tendency to pitting been overcome.

CASE II.-Mrs. Y., aged 32, a strong and stoutly made lady, was confined of a healthy boy on December 7 th, 1871 , and on the day following was attacked by confluent small-pox. Under the circumstances, the greatest danger was, of course, to be apprehended, and I was, therefore, exceedingly anxious. The same treatment as in Case I was employed, and with the like satisfactory results, with the one exception that, at this date, very slight pitting can be perceived, if looked for. The baby was vaccinated before it was twenty-four hours old, and it did not take small-pox.

One more case will suffice to show that this treatment is deserving of a more extensive trial. On December 2oth, 1872, I was asked to take charge of two ladies, mother and daughter, suffering from small-pox, their own medical man declining to attend. I found the mother prostrated by an attack of confluent small-pox, and her daughter suffering from the same disease, but of the discrete variety. The features in the elder patient were quite obliterated. The same treatment was adopted in .both cases, with the effect of giving almost instant relief. As the disease held on in its course, the last named patient showed slight symptoms of prostration; and, although I was not apprehensive myself, I thought it better to have a consultation with the gentleman who then had charge of the Fever Hospital in this city. He took a very unfavourable view of the patient's condition, and gave it as his opinion that the case would probably terminate fatally when the secondary fever set in; but, as this symptom never showed itself, this danger was avoided, and my patient made a rapid recovery. It is now impossible to detect any disfigurement from pitting.

\section{CASE OF POISONING BY BELLADONNA LINIMENT.*}

By JOHN MEREDITH, M.D., Wellington, Somerset.

IN September I875, I gave a patient, a lady aged between fifty and sixty years, four ounces of methylated belladonna liniment for the relief of some muscular pains from which she was suffering. I gave her also a bottle of medicine to be taken at intervals. The liniment was properly marked, and with directions for use.

In a few days afterwards (on October Ist), I was called to see her between seven and eight o'clock in the morning, the messenger saying she had taken a dose of the wrong medicine in mistake, and was very ill. A little before seven o'clock that morning, she went to her medicinebottle, as she imagined, and took a tablespoonful of the mixture, walked out of her room and downstairs, and mentioned to some one there that her medicine had a curious taste. "In about five minutes", to use her own words, she "felt queer about her eyes, then sturidlike" in her head ; felt she was losing the power of standing on her legs. She managed, however, to get back to her room, and there discovered what she had done, and told one of the servants of it. She took some" pills she had by her "to carry the thing off", as she put it, then added she should soon die. She became helpless and quite unconscious.

Before she reached this state, some salt and water were given to her, with the view of inclucing vomiting, but without the desired result. I cannot say precisely how soon after taking the poison the unconscious state was established, but it was in much less than an hour; for it was about this time when I reached the house and saw the patient. I tried to get her to swallow some mustard and water, but failed. She could swallow only a few drops of water, and very soon she became unable to do this. She could not speak; only numbled inces. santly some inarticulate words, which were only audible at times.

* Read before the West Somerset Branch.
She was put into bed, and there sat propped up by pillows, and had a vacant drunken look; moved her hands about, sorting and catching at imaginary things; being in this respect very much like a tailor who was poisoned by belladonna, and who, according to the report of his case, "sat for hours moving his hands and arms as if sewing and his lips as if talking, but without uttering a word". In short, she was in a state of somnambulism, barring the ambulation; for in this, as in similar cases recorded, there was no power over the lower extremities, while the upper ones moved about with comparative freedom.

The other characteristic features of the case at this stage were the widely dilated pupils, and a diffuse scarlet rash, which was out on the neck and upper part of the chest, and also on the hands and forearms. I did not examine other parts of the body; if I had, most likely I should have found it equally conspicuous all over, showing how general was the paralysis of the vaso-motor nerves throughout the cuticular system.

At this stage and very soon after my arrival, the all-important question, whether I thought the patient would recover, was put to me. To this, I replied at once that I believed she would. I felt justified in saying this, because fatal poisoning by belladonna is rare, but chiefly from my recollection of a case of atropia-poisoning which was reported some years ago, where the symptoms described were very similar to those of the case before me. I need hardly say how satisfactory it was to be able to give an assurance of this sort in a house where all were in consternation, and visions of "crowner's quest", as the master of it put it, were looming in apparently close proximity.

The rash was not of long duration; it soon began to fade, and in four hours was hardly perceptible anywhere. The pulse was of fair strength all through : above 80 , but not once up to I00. The respirations were normal, not markedly accelerated. Eight hours after taking the liniment, i.e., at 3 P.M., slight signs of recovering were observed. The patient was able to swallow a little coffee. She had passed no urine up to this time. An enema of warm water with some spirits of turpentine was given, and was retained. The bowels appeared also to have been paralysed for the time. At 9 P.M., the improvement was decided. She was able to swallow and speak a little, and passed urine; but the bowels had not acted, nor was there any sickness or nausea. Next day, when I called to see her-that was about twenty-six hours after the accident-the patient expressed herself as "feeling all right"; that, however, was not strictly the case with her. She had passed the night in a similar way to which she had passed the preceding day : restless, looking and acting as if she would go off to sleep, but never really doing so.

She remembered nothing of what had happened to her from the time she took the salt and water on the morning of the rst until about 5 o'clock of the 2 gd. For about twenty-two hours, her life was a blank to her. Her condition on the morning of the and was as follows. Her pupils were widely dilated, and she saw persons and things double, and at times saw imaginary persons and objects about her; her hands felt moist, as did also her feet, and she could not stand; but she was able to move her arms about all right. The bowels recovered their power and acted during the morning. On the third day, she was much better, only her sight was still dim and she felt very unsteady on her feet.

I should mention that all through there was a good deal of distress about the throat; it was one of the first things experienced, and the discomfort lasted, to a certain extent, for many days. The patient eventually recovered completely ; but, for several days, she felt she was not her ordinary self : could not remember how to do the simplest thing; had forgotten the way; had to ponder over the way an article of clothing should be fastened on, etc.

Nothing was done in the way of special treatment beyond keeping close watch over the case, and placing the patient in as comfortable a position in bed as was practicable.

I judge that about four drachms of the liniment were swallowed, equivalent to about twelve grains of camphor, besides the macerated juice of about half an ounce of belladonna-root, in addition to the spirits forming the liniment. This manifestly is an effective way of taking belladonna, and a way that brings out its action speedily. How far this action of belladonna was affected by the camphor I cannot say. The physiological effects of camphor are not, as far as I have been able to learn, clearly known. There is something of caprice attributed to them. The truth, after all, lies, I take it, in the fact that the properties of the drug have not been sufficiently investigated.

One of the acknowledged actions of camphor in considerable doses is to depress the respiration and the action of the heart; while atropia quickens respiration in an extraordinary manner. Such being the case, the two drugs taken at the same time would modify the 
action of one another; and this, I infer, was the cause of there being nothing particular to note in regard to the character of the respiration in the case under notice. Recent investigators tell us that atropiawhich, for my present purpose, I take as synonymous with belladonna -always produces paralysis of the posterior part of the body in animals. This observation applied well to my case, where loss of power over the lower limbs began early, soon became complete, and remained so for many hours; whereas the upper extremities were not so affected.

There is an observation I would like to make regarding the deduc. tion which has been made by Hahnemann and his followers in reference to the scarlet rash and throat discomfort produced by belladonna. Conditions resembling these are among the great characteristics of scarlatina, and on the principle-if a mere semblance can be designated by such a name-then, on the principle of similia similibus curantur, they have claimed for this drug the virtues of a specific as well as a prophylactic in that complaint.

The controversy on this point has been carried on in an acrimonious spirit, one party declaring for the efficacy of the medicine in this respect with all the fervid enthusiasm of a faith, while another scouts the thing as a mere illusion; so that between them it has come to this : that the profession, as a body, knows hardly anything more of the properties of belladonna touching this matter than it did four score years ago, vihen Hahnemann first launched his plausible theory on the world.

If the doctrine of similars is to hold, why is copaiva not taken up as being a specific for measles, since it produces a rash not distinguishable from that of measles, except in there being no fever? and this applies just as well to belladonna.

The only other remark I would like to offer is, that I was aware that, in our literature regarding belladonna-poisoning, morphia is stated to be the antidote in such cases. Possibly, if I had given a dose of morphia in this case, recovery might have taken place sooner; it could not have been more complete, however, and I preferred acting according to what seemed to me at the time the safest course.

\section{SURGICAL MEMORANDA.}

\section{LARGE SINUSES AND ABSCESS CAVITIES TREATED BY HYPERDISTENSION WITH DILUTED CARBOLIC ACID.}

Previously to reading Mr. Callender's paper in the Journal of No-

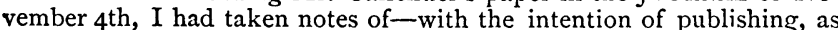
the results were very gratifying - a case of profuse suppuration following phlegmonous erysipelas, treated in a similar manner to that described by Mr. Callender; viz., by forcibly distending and washing out the affected tissues with warm carbolised solution, but without the use of the drainage-tube. The facts are as follows. J. M., a carter, aged 24 , receiving good wages and certainly not temperate, in getting down from his 'cart, met with a deep abrasion of the skin on the inner side of the right knee, extending somewhat posteriorly towards the popliteal space. The wound took on an erysipelatous action, the erysipelas extending very rapidly, with very great general prostration, upwards towards the abdomen, over both the front and back of the thigh and buttock to the loin, and downward over and around the leg, ankle, and foot. The boggy condition of deep phlegmon was never marked; but two incisions were made over the outside of the thigh, but gave exit to no pus. After two days, however, the presence of pus became evident, and the original wound near the knee was enlarged: but the destruction of the subcutaneous tissues went on so rapidly, from ankle to buttock, that, to give exit sufficiently to the stinking pus, many and free incisions were the distinctive means of treatment. Such measures were impracticable, as the patient and friends resolutely refused to allow any further use of the knife. Under such adverse circumstances, poultices were ordered ; and, with a discharge most profuse and offensive, after a week's interval the tissues were in the following condition. Over the right buttock was sound skin, but undermined tissues fluctuating distinctly; down the outside of the thigh, the skin was undermined and fluctuating ; the popliteal space was in the same condition, and forming a purulent reservoir, but with two ulcerated openings at the sides, through which pus could by manipulation be pressed. The subcutaneous structures around the ankle and two-thirds up the leg were unsound, and discharging profusely. There was one ulcerated opening over the inner malleolus. The poultices were continued for about five days ; but, as the discharge seemed in no way to decrease, it was determined to discontinue them, and make use of an injection of sulphate of copper (two grains to the ounce); the pain, however, was so great that it was not repeated. Carbolic acid was substituted (about one to twenty), warmed by the addition of a little boiling-water, and injected to distension once a day for about a week. The discharge was almost at once arrested, and, with the use of a light wet bandage, the immense undermined cavities soon united to the deeper parts and became sound; and, the weakness and stiffness of the limb gradually subsiding, after about six months the man was in a condition to resume his work, not one of these immense sinuses having been opened.

SAMUel PRALL, F.R.C.S., West Malling.

\section{CASES OF HERNIA IN PRIVATE PRACTICE.}

THE reports in the medical journals are for the most part those of hospital cases, but a short record of five consecutive cases of operation for strangulated hernia in private practice may be no less interesting.

CASE I.-J. R., male, aged 6o, intemperate, had a right inguinal hernia of about two years' duration, about the size of a walnut. It had been reducible till two days before operation : it contained gut only. A truss had been worn. The operation was performed under chloroform with perfect result, enabling the patient eventually to do without any truss. The parts remained perfectly solid three years after operation.

CASE II.-M. S., female, married, aged 53, had a left femoral hernia of several years' duration, as a result of a severe confinement. It had been strangulated four days when I was sent for to operate by the surgeon in charge. The operation was performed as a last hope, with very little chance of success. She would not take an anæsthetic. The part became very dark and congested; the omentum was much congested. The patient died of tetanus three days after the operation. There was no necropsy.

CASE III.-L. H., female, married, aged 32, had a left femoral hernia, following confinement, about a year ago. She had worn no truss. Strangulation occurred after violent exercise. I operated with chloroform and ether on the third day. An obscure diagnosis of a small bit of gut behind an enlarged gland was confirmed by the operation. The seat of strangulation was at Gimbernat's ligament : the orifice was very small. The operation was completely successful. No truss was worn a few months after the operation.

CASE IV. - R. T., male, aged 72, had a right scrotal hernia of long duration, reducible till yesterday, the day before I saw him. He had stercoraceous vomiting and hiccough. The hernia was reduced under chloroform, which was given with the intention of operating.

CASE v.-W. W., male, aged 54, had a right femoral hernia of about seven years' duration, containing gut and mesentery. The gut had been reducible till four days before operation, but the mesentery was adherent. The operation was staved off for three days by the use of the pneumatic aspirator, which gave relief and promised success; but stercoraceous vomiting set in on the fourth day, and an operation was performed under ether and chloroform. The seat of stricture was at Gimbernat's ligament, very small and tight. The mesentery was not interfered with. He is obliged to wear a truss, as the parts are not very strong. He can walk several miles.

Herbert M. Morgan, Lichfield.

\section{NOTES OF THREE CASES OF VESICAL CALCULUS.}

THE following cases are brought forward not because there is anything remarkable in them, but with a view of encouraging my fellow country practitioners not to look upon stone as a disease which can only be treated by specialists.

CASE I was a boy, T. F., aged 5, who had suffered from great pain during and after micturition from his infancy, and subsequently from entire inability to retain his urine, which constantly drained away from him. On examination, a calculus was readily detected, and a few days afterwards the boy was placed under the influence of chloroform, and the lateral operation commenced. The knife was soon in the groove of the staff, and pressed onwards into what seemel to be the bladder. The forefinger easily reached the stone; the staff was withdrawn; but, on attempting to seize the stone with forceps, it sullenly receded beyond their reach, and what had seemed to be the bladder was a sacculated enlargement of the urethra. A probe-pointed bistoury was passed along the forefinger, and the neck of the blad ler notched sufficiently to let the forceps pass, when the stone was easily removed. The patient made an excellent recovery, and was running about in the village where he lived within a week. The calculus, which consisted of uric acid, was of the shape of an hour glass, the extremity in the blad- 